\title{
Pengaruh waktu celup dan tegangan listrik terhadap hasil elektroplating bahan baja karbon rendah
}

\author{
Asroni $^{*}$, Nurlaila Rajabiah ${ }^{2}$, Dien Fahlevi ${ }^{3}$ \\ 1,2Jurusan Teknik Mesin, Fakultas Teknik, Universitas Muhammadiyah Metro \\ JI. Ki Hajar Dewantara 15 A Kota Metro, Lampung, Indonesia \\ ${ }^{3}$ Prodi Teknik Mesin, Fakultas Teknik, Universitas Muhammadiyah Metro \\ JI. Ki Hajar Dewantara 15 A Kota Metro, Lampung, Indonesia \\ ${ }^{*}$ Corresponding author: asroni14@yahoo.com
}

\begin{abstract}
Electroplating is a process of electro precipitation a metal layer on an electrode which aims to form a surface with different properties or dimensions from the base metal. The metal that is coated is aluminum because it is frequently used as industrial equipment, motor vehicle parts and so on. Low carbon steel is the steel most widely used as a shipbuilding material. As a mode of transportation that operates in corrosive marine environments, a coating protection is needed so that corrosion can be minimized. This study aims to determine the effect of immersion time and electric voltage on the optimal thickness of the electroplating results. Determine the effect of immersion time and electric voltage on the adhesive strength resulting from electroplating. Anode Material coated with ST41 Steel Plate with dimensions of $70 \times 25 \times 20 \mathrm{~mm}$. while the cathode uses nickel (Ni) with dimensions of $10 \times 20 \times 20 \mathrm{~mm}$. Cathode to anode distance of $10 \mathrm{~cm}$. Dip time 10, 15 and 20 minutes, adhesion testing using PosiTest AT-M Adhesion Tester. The conclusion obtained from this research is that the optimal thickness of the layer is at a voltage variation of 4 volts and immersion time used for 20 minutes with the results obtained of $0.093 \mathrm{~mm}$. While the adhesive strength of the layers from electroplating research was found in the variation of the voltage of 4 volts and the immersion time used for 20 minutes with the results obtained at $21.46 \mathrm{MPa}$.
\end{abstract}

Keywords: Electroplating, Nickel, anode, cathode, low carbon steel.

\begin{abstract}
Abstrak
Elektroplating merupakan suatu proses pengendapan elektro lapisan logam pada elektroda yang bertujuan membentuk permukaan dengan sifat atau dimensi yang berbeda dengan logam dasarnya. Logam yang dilapisi adalah alummunium karena sering digunakan sebagai peralatan industri, bagian kendaraan bermotor dan lain sebagainya. Baja karbon rendah adalah baja yang paling banyak digunakan sebagai bahan pembuatan kapal. Sebagai moda transportasi yang beroperasi pada lingkungan laut yang korosif, maka diperlukan suatu perlindungan coating agar korosi yang terjadi bisa diperkecil. Tujuan dari penelitian adalah untuk mengetahui pengaruh waktu celup dan tegangan listrik terhadap ketebalan yang optimal hasil dari electroplating. mengetahui pengaruh waktu celup dan tegangan listrik terhadap kekuatan lekat hasil dari electroplating. Anoda Bahan yang dilapisi Baja Plat ST41 dengan dimensi 70 × 25 × $20 \mathrm{~mm}$. sedangkan katoda menggunakan nikel (Ni) dengan dimensi 10 x 20 x $20 \mathrm{~mm}$. Jarak katoda dengan anoda $10 \mathrm{~cm}$. Waktu celup 10 menit, 15 menit, dan 20 menit, Pengujian kerekatan menggunakan PosiTest ATM Adhesion Tester. Kesimpulan yang di dapat dari peneltian ini yaitu ketebalan optimal lapisan terdapat pada variasi tegangan 4 volt dan waktu pencelupan yang di pakai selama 20 menit dengan hasil yang di peroleh sebesar $0.093 \mathrm{~mm}$. Sedangkan kekuatan lekat lapisan dari penelitian electroplating terdapat pada variasi tegangan 4 volt dan waktu pencelupan yang di pakai selama 20 menit dengan hasil yang di peroleh sebesar $21.46 \mathrm{MPa}$.
\end{abstract}

Kata kunci: Elektroplating, Nikel, anoda, katoda, baja karbon rendah. 


\section{Pendahuluan}

Kehidupan masyarakat Indonesia khususnya di Provinsi Lampung tepatnya di Kota Metro dalam kondisi modern ini tidak terlepas dari yang namanya teknologi dalam bidang teknik dan masih banyak lagi inovasi yang belum terselesaikan hingga saat ini dalam pencapaiannya untuk membuat benda-benda dengan menggunakan proses elektroplating. "Di kota metro ini masih sangat susah bahkan belum ditemukan jasa yang menyediakan pelapisan menggunakan proses elektroplating secara langsung" pendapat ini didapat karena penulis telah melakukan survei dari sepuluh bengkel di sudut-sudut Kota Metro dari penjuru barat, timur, selatan, utara dan Metro Pusat pada tahun 2019 [3]. Tentunya hal ini sangat menyulitkan bagi kebutuhan masyarakat di Kota Metro supaya bagaimana materialmaterial yang digunakan dalam kebutuhan seperti aksesoris marble, komponenkomponen dekorasi seperti spare part motor, mobil dan masih banyak lagi alat-alat berjenis baja karbon rendah khususnya baja "ST41" yang proses pengerjaan akhirnya (finishing) belum banyak menggunakan proses elektroplating/pelapisan dengan listrik. Dan apabila masyarakat Kota Metro ingin melakukan pelapisan listrik seperti krom, nikel, tembaga dll maka mereka akan mengirimkan bahan meterial tersebut ke luar wilayah Kota Metro.

\section{Tinjauan Teoritis}

\section{Elektroplating}

Elektroplating yaitu proses pelapisan logam dengan lgam lain didalam suatu larutan elektrolit dengan pembiasan arus listrik. Konsep yang digunakan dalam proses elektroplating adalah konsep reaksi reduksi dan oksidasi dengan menggunakan sel elektrolisa. Dalam sel elektrolisa arus yang akan dialirkan akan menimbulkan reaksi reduksi dan oksidasi dengan mengubah energi listrik menjadi energi kimia. Proses pelapisan terjadi jika suatu benda yang akan dilapisi berfungsi sebagai katoda dan benda pelapis sebagai anoda dicelupkan ke dalam larutan elektrolit dengan konsentrasi tertentu, kemudian arus dialirkan ke dalam larutan tersebut maka ion-ion pada anoda akan terurai ke dalam larutan dan akan melapisi benda yang akan berfungsi sebagai katoda. Banyaknya ion yang diuraikan tergantung dari besarnya arus yang dialirkan. Semakin besar arus yang dialirkan semakin banyak ion yang diuraikan begitu pula sebaliknya.

\section{Baja karbon rendah}

Baja karbon rendah adalah baja yang paling banyak digunakan sebagai bahan pembuatan kapal. Sebagai moda transportasi yang beroperasi pada lingkungan laut yang korosif, maka diperlukan suatu perlindungan coating agar korosi yang terjadi bisa diperkecil. Pada pengujian ini, coating sengaja divariasikan ketebalannya. Hal ini mengacu pada tidak meratanya proses coating pada pelat lambung kapal, dikarenakan pengerjaan coating dilakukan secara manual dengan area yang dicat cukup luas. Sehingga kemungkinan terlalu tebal ketebalan coating bisa saja terjadi di area tertentu. Sistem coating yang diuji ada dua, yaitu sistem coating dua lapis dengan menggunakan cat Alkyd dan sistem tiga lapis dengan menggunakan cat Epoxy. Pengujian dan perhitungan laju korosinya dengan menggunakan metode elektrokimia. Dari hasil perhitungan dapat disimpulkan bahwa semakin tebal lapisan suatu coating tidak menjamin coating tersebut dapat melindungi dengan sempurna. Semakin tebal suatu coating memiliki resiko kegagalan coating lebih besar seperti, berkurangnya fleksibilitas, terjadinya pengerutan, atau pengeringan yang tidak sempurna [4].

\section{Nikel}

Nikel merupakan salah satu bahan tambang mineral logam dengan lambang unsur Ni. Unsur Ni sangat reaktif dengan oksigen sehingga keberadaan nikel di alam berupa senyawa. Walaupun nikel bersifat reaktif terhadap oksigen, akan tetapi tidak mengalami korosi, sehingga mempunyai peranan penting dalam industri baja. Campuran nikel dengan krom dan besi menghasilkan baja tahan karat yang biasa disebut baja nirkarat (stainless steel). 
Nikel (Ni) adalah logam yang mempunyai sifat fisik antara lain berwarna putih mengkilat, sangat keras, tidak berkarat dan tahan terhadap asam encer. Oleh karena itu penggunaannya banyak diperuntukan untuk melapisi barang yang terbuat dari besi, tembaga dan baja karena nikel mempunyai sifat keras, tahan korosi dan mudah mengkilat bila digosok. Selain itu, nikel digunakan juga untuk membuat baja nirkarat dan alloy atau campuran nikel dengan tembaga atau beberapa logam lain yang penting untuk industri. Beberapa contoh alloy adalah Monel, yaitu campuran nikel dengan tembaga dan besi $(\mathrm{Ni}, \mathrm{Cu}, \mathrm{Fe})$ digunakan untuk membuat instrumen transmisi listrik, Nikrom (Ni, Fe, Cr) digunakan sebagai kawat pemanas, dan Alniko ( $\mathrm{Al}, \mathrm{Ni}, \mathrm{Fe}, \mathrm{Co}$ ) digunakan untuk membuat magnet [5].

\section{Metode Penelitian}

Alat

1) Power Supply

2) Multitester

3) Stopwatch

4) Micrometer

5) Gerindra

6) Amplas

7) PosiTest AT-M Adhesion Tester

\section{Bahan}

1) Amplas

2) Baja Karbon Rendah

3) Logam Nikel

4) Nikel Sulfat $\left(\mathrm{NiSO}_{4}\right)$

5) Larutan Asam Sulfat $\left(\mathrm{H}_{2} \mathrm{SO}_{4}\right)$

6) Kabel

7) Aquades

\section{Prosedur Penelitian}

1. Mempersiapkan bahan, dalam hal ini pelat baja karbon rendah (katoda).

2. Mempersiapkan larutan elektrolit asam sulfat (H2SO4) 1 liter.

3. Pembuatan spesimen, memotong pelat baja dengan dimensi $70 \mathrm{~mm} \mathrm{x}$ $25 \mathrm{~mm}$ x $20 \mathrm{~mm}$.

4. Membersihkan dan menghaluskan permukaan spesimen menggunakan gerinda.
5. Mengukur ketebalan spesimen untuk mengetahui perbandingan setelah pengujian.

6. Merendam spesimen dengan menggunakan larutan alkali selama 5 menit.

7. Keringkan spesimen dengan suhu ruangan.

8. Menghubungkan spesimen pada arus listrik negatif.

9. Menghubungkan logam nikel pada arus listrik positif.

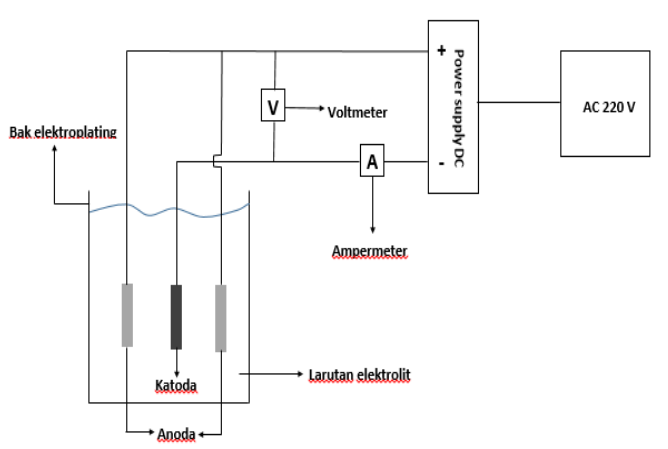

Gambar 1. Skema Elektroplating

\section{Hasil dan Pembahasan}



Gambar 2. grafik ketebalan lapisan pada tegangan 3 volt

Pada grafik Gambar 3, dapat dilihat pada tegangan 3 volt dengan waktu pencelupan 10 menit mendapatkan nilai ketebalan sebesar $0.011 \mathrm{~mm}$, sedangkan waktu pencelupan selama 15 menit mendapatkan nilai ketebalan sebesar 0.025 mm dan waktu pencelupan selama 20 menit mendapatkan nilai ketebalam sebesar 0.033 $\mathrm{mm}$. 


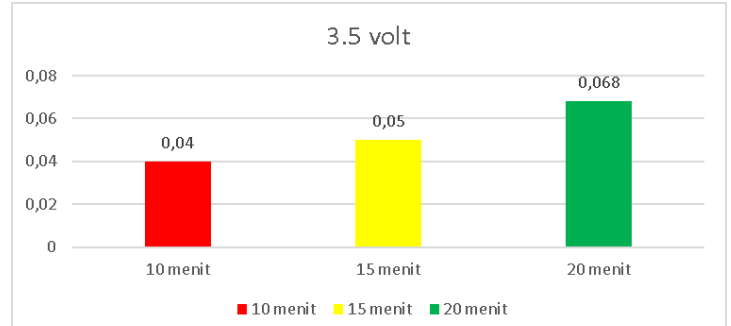

Gambar 3. Grafik ketebalan lapisan pada tegangan 3.5 volt.

Pada grafik Gambar 3, dapat dilihat pada tegangan 3.5 volt dengan waktu pencelupan 10 menit mendapatkan nilai ketebalan sebesar $0.04 \mathrm{~mm}$, sedangkan waktu pencelupan selama 15 menit mendapatkan nilai ketebalan sebesar 0.05 $\mathrm{mm}$ dan waktu pencelupan selama 20 menit mendapatkan nilai ketebalan sebesar 0.068 $\mathrm{mm}$.

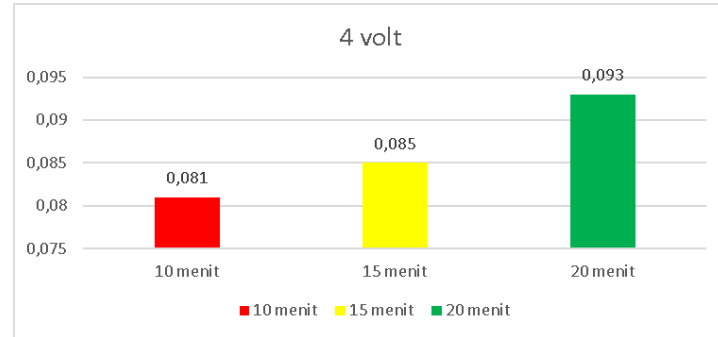

Gambar 4. Grafik ketebalan lapisan pada tegangan 4 volt.

Pada grafik Gambar 5, dapat kita lihat pada tegangan 4 volt dengan waktu pencelupan 10 menit mendapatkan nilai ketebalan sebesar $0.081 \mathrm{~mm}$, sedangkan waktu pencelupan selama 15 menit mendapatkan nilai ketebalan sebesar 0.085 mm dan waktu pencelupan selama 20 menit mendapatkan nilai ketebalam sebesar 0.093 $\mathrm{mm}$.

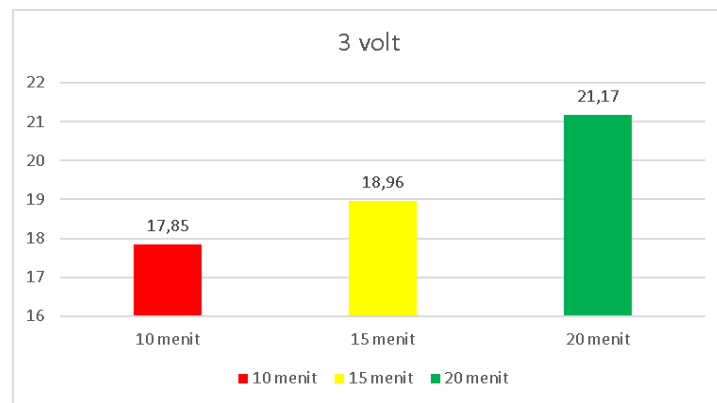

Gambar 5. Grafik kuat lekat lapisan pada tegangan 3 volt.
Pada grafik Gambar 5, dapat dilihat pada tegangan 3 volt dengan waktu pencelupan 10 menit mendapatkan nilai kuat lekat sebesar $17.85 \mathrm{MPa}$, sedangkan waktu pencelupan selama 15 menit mendapatkan nilai kuat lekat sebesar $18.96 \mathrm{MPa}$ dan waktu pencelupan selama 20 menit mendapatkan nilai kuat lekat sebesar 21.17 MPa.

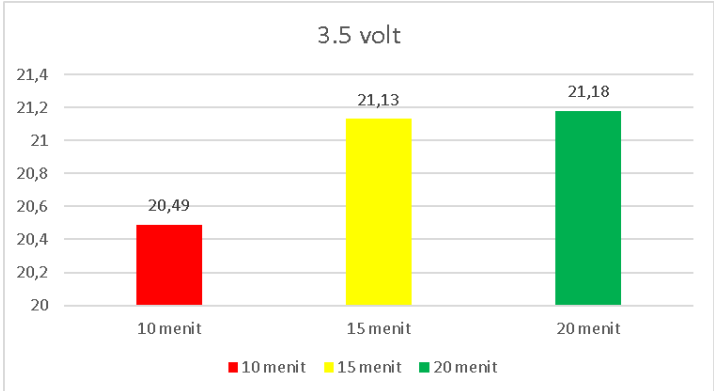

Gambar 6. Grafik kuat lekat lapisan pada tegangan 3.5 volt.

Pada grafik Gambar 6, dapat dilihat pada tegangan 3.3 volt dengan waktu pencelupan 10 menit mendapatkan nilai kuat lekat sebesar $20.49 \mathrm{MPa}$, sedangkan waktu pencelupan selama 15 menit mendapatkan nilai kuat lekat sebesar $21.13 \mathrm{MPa}$ dan waktu pencelupan selama 20 menit mendapatkan nilai kuat lekat sebesar 21.18 MPa.

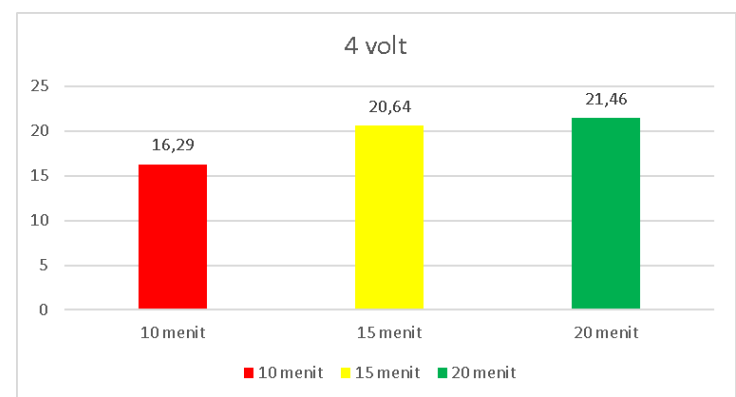

Gambar 7. grafik kuat lekat lapisan pada tegangan 4 volt.

Pada grafik di atas dapat kita lihat pada tegangan 4 volt dengan waktu pencelupan 10 menit mendapatkan nilai kuat lekat sebesar 16.29 MPa, sedangkan waktu pencelupan selama 15 menit mendapatkan nilai kuat lekat sebesar $20.64 \mathrm{MPa}$ dan waktu pencelupan selama 20 menit mendapatkan nilai kuat lekat sebesar 21.46 MPa. 


\section{Kesimpulan}

Kesimpulan yang didapat dari peneltian ini yaitu, ketebalan optimal lapisan dari penelitian electroplating terdapat pada variasi tegangan 4 volt dan waktu pencelupan yang dipakai selama 20 menit dengan hasil yang di peroleh sebesar $0.093 \mathrm{~mm}$.

Sedangkan kekuatan lekat lapisan dari penelitian elektroplating terdapat pada variasi tegangan 4 volt dan waktu pencelupan yang di pakai selama 20 menit dengan hasil yang di peroleh sebesar 21.46 MPa.

\section{Referensi}

[1] Tamprin, M. (2013). Studi Pelapisan Krom dengan Proses Elektroplating pada Handel Rem Sepeda Motor dengan Variasi Rapat Arus. Electronic Theses and Dissertations, 1-10.

[2] Afandi, Y. K. (2015). Analisa Laju Korosi pada Pelat Baja Karbon dengan Variasi Ketebalan Coating. Jurnal Teknik ITS, 1-5.

[3] Permadi, B., Asroni, A., \& Budiyanto, E. (2020). Proses elektroplating nikel dengan variasi jarak anoda katoda dan tegangan listrik pada baja ST41. Turbo: Jurnal Program Studi Teknik Mesin, 8(2).

[4] Afandi, Y. K. (2015). Analisa Laju Korosi pada Pelat Baja Karbon dengan Variasi Ketebalan Coating. Jurnal Teknik ITS, 1-5.

[5] Pardiarto. (2013, 6 12). NIKEL, KOMODITAS LOGAM STRATEGIS. Retrieved from Geomagz. 